\title{
Burkholderia cenocepacia requires RpoE for growth under stress conditions and delay of phagolysosomal fusion in macrophages
}

\section{Correspondence \\ Miguel A. Valvano \\ mvalvano@uwo.ca}

Received 27 September 2007

Revised 28 October 2007

Accepted 5 November 2007

\author{
Ronald S. Flannagan ${ }^{1}$ and Miguel A. Valvano ${ }^{1,2}$ \\ ${ }^{1}$ Infectious Disease Research Group, Department of Microbiology and Immunology, University of \\ Western Ontario, London, Ontario, Canada \\ ${ }^{2}$ Medicine, Siebens-Drake Research Institute, University of Western Ontario, London, Ontario, \\ Canada
}

\begin{abstract}
Burkholderia cenocepacia is an opportunistic pathogen causing serious infections in patients with cystic fibrosis. The widespread distribution of this bacterium in the environment suggests that it must adapt to stress to be able to survive. We identified in B. cenocepacia K56-2 a gene predicted to encode $\mathrm{RpoE}$, the extra-cytoplasmic stress response regulator. The rpoE gene is the first gene of a predicted operon encoding proteins homologous to RseA, RseB, MucD and a protein of unknown function. The genomic organization and the co-transcription of these genes were confirmed by PCR and RT-PCR. The mucD and rpoE genes were mutated, giving rise to $B$. cenocepacia RSF24 and RSF25, respectively. While mutant RSF24 did not demonstrate any growth defects under the conditions tested, RSF25 was compromised for growth under temperature $\left(44^{\circ} \mathrm{C}\right.$ ) and osmotic stress $(426 \mathrm{mM} \mathrm{NaCl})$. Expression of RpoE in trans could complement the osmotic growth defect but exacerbated temperature sensitivity in both RSF25 and wild-type K56-2. Inactivation of $r p o E$ altered the bacterial cell surface, as indicated by increased binding of the fluorescent dye calcofluor white and by an altered outer-membrane protein profile. These cell surface changes were restored by complementation with a plasmid encoding rpoE. Macrophage infections in which bacterial colocalization with fluorescent dextran was examined demonstrated that the rpoE mutant could not delay the fusion of $B$. cenocepacia-containing vacuoles with lysosomes, in contrast to the parental strain K56-2. These data show that $B$. cenocepacia rpoE is required for bacterial growth under certain stress conditions and for the ability of intracellular bacteria to delay phagolysosomal fusion in macrophages.
\end{abstract}

\section{INTRODUCTION}

The Burkholderia cepacia complex (Bcc) comprises a group of nine closely related bacterial species that are phenotypically very similar but genetically distinct (Coenye et al., 2003; Mahenthiralingam et al., 2000). These bacteria are opportunistic pathogens that cause infections in immunocompromised individuals and often infect cystic fibrosis (CF) patients (Mahenthiralingam \& Vandamme, 2005). Burkholderia cenocepacia, a member of the Bcc, is one of the species most often recovered from CF patients worldwide and is also associated with the most severe infections (Brisse et al., 2004; LiPuma, 2005; Manno et al., 2004; Reik et al., 2005; Speert et al., 2002). Furthermore, B. cenocepacia infections in CF patients are associated with an accelerated decline in lung function as compared to

Abbreviations: Bcc, Burkholderia cepacia complex; BcCV, B. cenocepacia-containing vacuole; CF, cystic fibrosis; OM, outer membrane; Tp, trimethoprim. other CF-related pathogens such as Pseudomonas aeruginosa (Courtney et al., 2004; Jones et al., 2004). The treatment of infection is difficult because this bacterium is multi-drug resistant (Zhou et al., 2007) and can be transmitted from person to person (Govan et al., 1993; LiPuma et al., 1990; Smith et al., 1993). Infections are further complicated by the 'cepacia syndrome', a potentially fatal necrotizing pneumonia that occurs in a subset of patients (Isles et al., 1984; Thomassen et al., 1985).

Although B. cenocepacia can be transmitted between patients, it is also acquired from environmental sources (Coenye \& Vandamme, 2003) as these bacteria occupy many different niches, including the rhizosphere, plants and humans. Therefore, it is likely that B. cenocepacia can readily adapt to many different stresses. One way by which bacteria adapt to stress is through the activity of the alternative sigma factor RpoE, a key regulator of the extracytoplasmic stress response that has been extensively characterized in the enteric bacterium Escherichia coli (De 
Las Peñas et al., 1997b; Raina et al., 1995). RpoE is normally sequestered to the cytoplasmic face of the inner membrane by an anti-sigma factor, RseA, and a periplasmic protein, RseB (De Las Peñas et al., 1997a; Missiakas et al., 1997). RseA is degraded under certain stress conditions by the concerted activities of the proteases DegS, YaeL and ClpXP (Alba et al., 2002; Chaba et al., 2007; Flynn et al., 2004; Kanehara et al., 2002), resulting in the release of RpoE into the cytosol.

In E. coli, where rpoE is essential (De Las Peñas et al., 1997b), a great deal of work has been done to determine which genes belong to the RpoE regulon (Dartigalongue et al., 2001; Rezuchova et al., 2003). Many of the genes identified are involved in membrane biogenesis or repair, protein folding or degradation, and they include rpoE itself along with its regulatory proteins (Dartigalongue et al., 2001). An example of an RpoE-regulated gene in E. coli is DegP, an HtrA-like protease that functions to degrade misfolded proteins in the periplasm (Dartigalongue et al., 2001; Lipinska et al., 1988). Previously, we characterized an HtrA protease from $B$. cenocepacia that is required for growth under certain stress conditions and for virulence (Flannagan et al., 2007) and this was the first evidence that the $B$. cenocepacia stress response is important for pathogenesis. Very little is known about which genes are required for the survival of $B$. cenocepacia under stress and the contribution of these genes to virulence. As a next step we wanted to characterize the master regulator of the extracytoplasmic stress response, RpoE, in B. cenocepacia. In this report we describe the creation and characterization of an $r p o E$ mutant and show that this gene is required for the maturation delay of the $B$. cenocepacia-containing vacuole $(\mathrm{BcCV})$ in a macrophage model of infection.

\section{METHODS}

Bacterial culture conditions and conjugations. Bacteria and plasmids used in this study are listed in Table 1. B. cenocepacia and E. coli were cultured at 30 and $37{ }^{\circ} \mathrm{C}$ in Luria-Bertani (LB) broth or LB agar. For growth under nutrient-limited conditions a modified M9 minimal medium was prepared from $5 \times$ M9 salts (Difco) supplemented with $0.2 \%$ (w/v; final concentrations) glycerol, $0.2 \%$ $(\mathrm{w} / \mathrm{v})$ glucose, $0.2 \%(\mathrm{w} / \mathrm{v})$. Casamino acids, $2.0 \mu \mathrm{g}$ vitamin $\mathrm{B} 1 \mathrm{ml}^{-1}$ and $20 \mu \mathrm{g}$ tryptophan $\mathrm{ml}^{-1}$. For antibiotic selection in E. coli $50 \mu \mathrm{g}$ trimethoprim $(\mathrm{Tp}) \mathrm{ml}^{-1}, 20 \mu \mathrm{g}$ tetracycline $\mathrm{ml}^{-1}$ and $40 \mu \mathrm{g}$ kanamycin $\mathrm{ml}^{-1}$ were used, while $100 \mu \mathrm{g} \mathrm{Tp} \mathrm{ml} \mathrm{g}^{-1}$ and $100 \mu \mathrm{g}$ tetracycline $\mathrm{ml}^{-1}$ were used for selection in B. cenocepacia. Plasmids were transferred into B. cenocepacia by tri-parental mating at $30{ }^{\circ} \mathrm{C}$ using E. coli $\mathrm{DH} 5 \alpha$ carrying the helper plasmid pRK2013 (Figurski \& Helinski, 1979). Gentamicin $\left(50 \mu \mathrm{g} \mathrm{ml}^{-1}\right)$ was used to counter-select against the E. coli donor and helper strains.

General molecular techniques. DNA manipulations were performed as described by Sambrook, et al. (1990). Restriction enzymes and T4 DNA ligase (Roche Diagnostics) and Antarctic phosphatase (New England Biolabs) were used as recommended by the suppliers. E. coli DH5 $\alpha$ and E. coli SY327 cells were transformed by the calcium chloride protocol (Cohen et al., 1972). DNA was amplified by PCR using the PTC-0200 DNA engine (MJ Research) with Taq DNA polymerase or Proof Start DNA polymerase (Qiagen). PCR reactions to amplify $B$. cenocepacia DNA were supplemented with Qiagen $\mathrm{Q}$ solution. DNA sequencing was performed at the DNA sequencing Facility at York University, Toronto, Ontario, Canada. The genome sequence of B. cenocepacia strain J2315 (http:// www.sanger.ac.uk/Projects/B_cenocepacia/) was analysed with the BLAST program.

Table 1. Strains and plasmids

\begin{tabular}{|c|c|c|}
\hline Strain/plasmid & Relevant characteristics ${ }^{\star}$ & Source/reference $\dagger$ \\
\hline \multicolumn{3}{|l|}{ B. cenocepacia } \\
\hline $\mathrm{J} 2315$ & CF clinical isolate & BCRRC \\
\hline K56-2 & ET12 clone related to J2315 & BCRRC \\
\hline RSF24 & K56-2, mucD:: pRFint-mucD, $\mathrm{Tp}^{\mathrm{R}}$ & This study \\
\hline RSF25 & $\mathrm{K} 56-2, r p o E:: \mathrm{pRFint}-r p o E, \mathrm{Tp}^{\mathrm{R}}$ & This study \\
\hline \multicolumn{3}{|l|}{ E. coli } \\
\hline $\mathrm{DH} 5 \alpha$ & 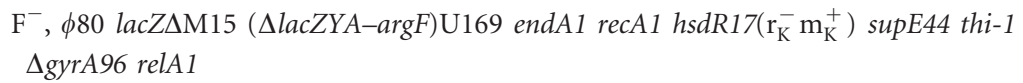 & Laboratory stock \\
\hline SY327 & araD,$\Delta($ lac pro $) \arg E(A m)$ recA56 rif ${ }^{R}$ nalA $\lambda$ pir & Miller \& Mekalanos (1988) \\
\hline \multicolumn{3}{|l|}{ Plasmids } \\
\hline pGP704 & $o r i_{\mathrm{R} 6 \mathrm{~K}}, \mathrm{Ap}^{\mathrm{R}}, \mathrm{mob}^{+}$ & Miller \& Mekalanos (1988) \\
\hline pDA17 & ori $_{\mathrm{pBBR} 1}, \mathrm{Tet}^{\mathrm{R}}, \mathrm{mob}^{+}, P_{d f r B 2}$, FLAG epitope & D. Aubert \\
\hline pRK2013 & ori $_{\text {colE1}}, \mathrm{RK} 2$ derivative, $\mathrm{Kan}^{\mathrm{R}}, \mathrm{mob}^{+}, \mathrm{tra}^{+}$ & Figurski \& Helinski (1979) \\
\hline pMLBAD & $o r i_{\mathrm{pBBR} 1}, \mathrm{Tp}^{\mathrm{R}}, m o b^{+}, \operatorname{araC}-P_{\mathrm{BAD}}$ & Lefebre \& Valvano (2002) \\
\hline pGPApTp & pGP704, $\mathrm{Tp}^{\mathrm{R}}, \mathrm{Ap}^{\mathrm{R}}, \mathrm{mob}^{+}$ & This study \\
\hline pRFint-rpoE & pGPApTp, 219 bp internal fragment from $r p o E$ & This study \\
\hline pRFint-mucD & pGPApTp, 291 bp internal fragment from $m u c D$ & This study \\
\hline pRF132 & pDA17, BCAL2829 FLAG & Flannagan et al. (2007) \\
\hline pRF135 & pDA17, rpoE & This study \\
\hline
\end{tabular}

${ }^{*}$ Tp, trimethoprim; Kan, kanamycin; Ap, ampicillin; Tet, tetracycline.

$\nmid$ BCRRC, B. cepacia Complex Research and Referral Repository for Canadian CF Clinics; D. Aubert, University of Western Ontario. 
Construction of the plasmid pGPApTp and inactivation of the mucD and rpoE genes. The mutagenesis plasmid pGPApTp was built to inactivate $m u c D$ and $r p o E$ in B. cenocepacia (Fig. 1). pGPApTp carries the R6K origin of replication and cannot replicate in the absence of the Pi protein (Filutowicz \& Rakowski, 1998). The dfrB2 gene from pMLBAD was PCR amplified using primers 548 ( $5^{\prime}-$ TCTACGGGGTCTGACGCTCAGTGGAACG-3') and 549 (5'AGGGATCCTAAGATATCGCTTAGGCCACACGTTCAAG-3'). The resulting $675 \mathrm{bp}$ amplicon was subsequently cloned into the EcoRV site of pGP704, giving rise to pGPApTp. The orientation of the $d f r B 2$ gene was confirmed by PCR analysis using the R6K ori primer 1300 (5'-TAACGGTTGTGGACAACAAGCCAGGG-3') and primer 549. To inactivate $m u c D$ an internal fragment of the gene was PCR amplified using primers 2217 (5' ${ }^{\prime}$-TTTTCTAGATCGACGATGCGGACACCATCTAC- $\left.3^{\prime}\right)$ and 2218 (5'-TTTTCTAGACAGGGTTCACGGCCACGTCGGTC-3') with the following thermal cycling conditions: $95{ }^{\circ} \mathrm{C}$ for $3 \mathrm{~min} 30 \mathrm{~s}$ followed by 30 cycles of $95{ }^{\circ} \mathrm{C}$ for $40 \mathrm{~s}, 62{ }^{\circ} \mathrm{C}$ for $40 \mathrm{~s}$ and $72{ }^{\circ} \mathrm{C}$ for $1 \mathrm{~min} 10 \mathrm{~s}$. The amplicon was digested with $\mathrm{XbaI}$ (sites underlined in primer sequences) and cloned into pGPApTp treated with the same enzyme and Antarctic phosphatase. The orientation of the cloned mucD internal fragment was the same as that of the $d$ frB2 gene and was confirmed by PCR using primers $612\left(5^{\prime}-\right.$ TCAAGGATCTTACCGCTGTTG-3') and 2217. The resultant plasmid was named pRFint-mucD. This mutagenesis plasmid was conjugated into B. cenocepacia K56-2 and Tp-resistant exconjugants were selected. Targeted integration of pRFint-mucD into the $m u c D$ gene was confirmed by PCR and Southern blot hybridization using a digoxigenin-labelled internal fragment from $m u c D$. The resultant strain was named B. cenocepacia RSF24. To mutate the rpoE gene an internal fragment was PCR amplified using primers 2215 (5'TTTGTCGACCGTGCGCTGCCGCAATTCCGCG-3') and 2216 (5'TTTGTCGACGTTGACCGTCTCGGCAATCTGCTTG-3') and the thermal cycling conditions described above. The resultant amplicon was digested with SalI and cloned into pGPApTp that had been similarly digested and treated with Antarctic phosphatase. The orientation of the $r p o E$ internal fragment was the same as that of the $d f r B 2$ gene and was confirmed by PCR using primers 612 and 2215. The resultant plasmid was named pRFint-rpoE. This mutagenesis plasmid was conjugated into B. cenocepacia K56-2 and mutants were confirmed

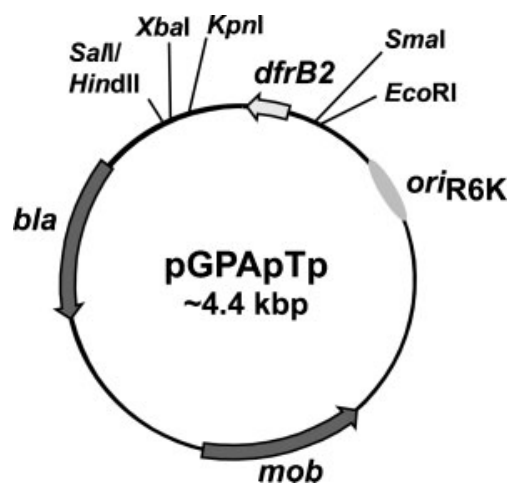

Fig. 1. Schematic map of the mutagenesis plasmid pGPApTp. The suicide plasmid pGPApTp carries the Pir-dependent R6K origin (ori $i_{\mathrm{R} 6 \mathrm{~K}}$ ) of replication. The $\beta$-lactamase (b/a) gene confers resistance to ampicillin and the dihydrofolate reductase ( $d f r B 2)$ gene confers resistance to trimethoprim. The mob element is required for conjugal transfer. The unique restriction sites for Sall, Hindll, Kpnl, Xbal, Smal and EcoRl are shown. as above except that a digoxigenin-labelled internal fragment from $r p o E$ was used. The resultant strain was named B. cenocepacia RSF25.

Southern blot hybridization. Chromosomal DNA was isolated from RSF25 and digested with XhoI. Digested DNA was separated by electrophoresis in a $0.7 \%(\mathrm{w} / \mathrm{v})$ agarose gel and was transferred to positively charged nylon membrane by capillary transfer. The rpoE internal fragment was labelled with digoxigenin-11-UTP by PCR using primers 2215 and 2216, a digoxigenin-labelling nucleotide mix (Roche) and Taq DNA polymerase. The membrane was hybridized with the probe under high-stringency conditions and hybridization was detected by chemiluminescence with disodium 3-(4-methoxyspiro\{1,2-dioxetane-3,2' - (5'-chloro)tricylco[3.3.1.1 $\left.1^{3,7}\right]$ decan $\}-4$-yl)phenyl phosphate (CSPD) as recommended by the manufacturer (Roche). The same procedure was followed for RSF24 except that the chromosome was digested with NotI and the probe used was the internal fragment from $m u c D$ labelled with digoxigenin.

RpoE expression plasmid. For complementation experiments the entire rpoE gene was PCR amplified from B. cenocepacia K56-2 genomic DNA using primers $2417\left(5^{\prime}\right.$-TTGAATTCGTGAGTGAAAAAGAAATCGATCAGGC-3' $)$ and 2418 (5' - TTTTCTAGACCAGCGCTTGCCTTCGGGCGTATC- $3^{\prime}$ ). The resulting PCR product was digested with EcoRI and $\mathrm{XbaI}$ (restriction sites are underlined in the primer sequences) and cloned into pDA17 that had been similarly digested. The resulting plasmid was named pRF135. The rpoE gene was cloned in-frame with and fused to the FLAG epitope coded for in pDA17. Expression of RpoE was confirmed by Western blot analysis of whole-cell lysates as described previously (Flannagan et al., 2007).

RT-PCR. RT-PCR was performed as described previously (Ortega et al., 2005) to investigate the transcriptional organization of the rpoE operon. Total RNA was isolated from B. cenocepacia K56-2 using the RNeasy Mini kit (Qiagen) following the manufacturers' protocol. Isolated RNA was treated with DNase (Qiagen) for $30 \mathrm{~min}$ at $37{ }^{\circ} \mathrm{C}$ and for $15 \mathrm{~min}$ at $75^{\circ} \mathrm{C}$. To amplify the intergenic regions, RT reactions using RNA treated with reverse transcriptase and without reverse transcriptase (negative control) were performed at $55{ }^{\circ} \mathrm{C}$ for $30 \mathrm{~min}$ followed by $5 \mathrm{~min}$ at $85^{\circ} \mathrm{C}$. These were used as templates for PCR using DNA as a positive control. The primers used for each gene are listed in Table 2 .

Osmotic sensitivity analysis. To expose $B$. cenocepacia to osmotic stress, bacteria were cultured at $30{ }^{\circ} \mathrm{C}$ in $\mathrm{LB}[1 \%(\mathrm{w} / \mathrm{v})$ tryptone, $0.5 \%(\mathrm{w} / \mathrm{v})$ yeast extract, $86 \mathrm{mM} \mathrm{NaCl}]$ or a modified LB medium (LB with $426 \mathrm{mM} \mathrm{NaCl}$ ) with an increased $\mathrm{NaCl}$ concentration. Cultures were started at $\mathrm{OD}_{600} 0.005\left(\sim 1.3 \times 10^{6}\right.$ bacteria $)$ and growth was determined in a 100-well disposable plate using a Bioscreen C automated microbiology growth curve analysis system (MTX Lab Systems). Growth was analysed using the low continuous shaking setting.

Table 2. RT-PCR primers

\begin{tabular}{|ll|}
\hline Primer & \multicolumn{1}{c|}{ Nucleotide sequence } \\
\hline 2757 (rseA RT F) & $5^{\prime}$-GCAATTCGCCCAGCAGCCCG-3' \\
$2758($ rseB RT R) & $5^{\prime}$-CGAACGTACCTTCGTAGCTCTGCTG-3' \\
$2759($ rseB RT F) & $5^{\prime}$-GTTGCAGCAGTTCGCGTCTGCC-3' \\
$2760($ mucD RT R) & $5^{\prime}$-GCACGTTGGCGGTGGTCCG-3' \\
$2761($ mucD RT F) & $5^{\prime}$-CGTGGCGACAACACGCAGTTC-3' \\
2762 (orf5 RT R) & $5^{\prime}$-CACACTTCCGCGCCGTCCAG-3' \\
$2776($ rpoE RT F $)$ & $5^{\prime}$-CGATGCGGAGGAAGCGGAAAC-3' \\
& \\
\hline
\end{tabular}


Temperature sensitivity. Temperature sensitivity was assessed by drop plating serially diluted $\left(10^{0}-10^{-5}\right)$ cell suspensions onto LB agar or modified M9 minimal agar. Bacteria from overnight cultures were used to set up cell suspensions at a starting $\mathrm{OD}_{600} 0.1\left(\sim 2.6 \times 10^{7}\right.$ bacteria). The plates were allowed to dry and then incubated at 30 or $44{ }^{\circ} \mathrm{C}$ for $24 \mathrm{~h}$.

Calcofluor binding. Bacteria were cultured overnight in LB at $30{ }^{\circ} \mathrm{C}$ with shaking. Overnight cultures were used to inoculate fresh LB and the cells were cultured again at $30{ }^{\circ} \mathrm{C}$ with shaking until they entered exponential phase $\left(\mathrm{OD}_{600}\right.$ 0.15-0.25). From these cultures cell suspensions were set up at $\mathrm{OD}_{600} 0.1 \quad\left(\sim 2.6 \times 10^{7}\right.$ bacteria $)$ and $10 \mu \mathrm{l}$ volumes of the suspensions were drop plated onto LB agar with $0.02 \%(\mathrm{w} / \mathrm{v})$ calcofluor white. Plates were incubated for $24 \mathrm{~h}$ at $30{ }^{\circ} \mathrm{C}$ then photographed under UV and white light using a ChemiDoc XRS system (Bio-Rad) with Quantity-One 1D analysis software (Bio-Rad). Light intensities of zones of growth were quantified using Odyssey 2.1 software from an Odyssey Infrared Imager (Li-Cor Biosciences). Statistical analyses were performed using GraphPad Prism 4.0 software.

Isolation of outer membrane (OM) proteins. OM proteins were isolated from B. cenocepacia following a modified version of the Sarkosyl insolubility protocol of Carlone et al. (1986). Bacteria were cultured overnight at $30{ }^{\circ} \mathrm{C}$ in $\mathrm{LB}$ and the cells were pelleted. The bacterial pellet was resuspended in $5 \mathrm{ml} 10 \mathrm{mM}$ Tris/ $\mathrm{HCl}(\mathrm{pH} \mathrm{8.0)}$ and lysed by sonic disruption until clear (approximately four $30 \mathrm{~s}$ pulses with a $40 \%$ amplitude). The lysate was pelleted in Eppendorf tubes and then centrifuged at $31191 \mathrm{~g}$ for $30 \mathrm{~min}$ at $4{ }^{\circ} \mathrm{C}$. The supernatant was removed and the pellet suspended in $500 \mu \mathrm{l}$ buffer [1.5\% (w/v) Sarkosyl, $20 \mathrm{mM}$ Tris/ $\mathrm{HCl} \mathrm{pH}$ 8.0] and incubated at room temperature for $20 \mathrm{~min}$. The samples were centrifuged as described above, the supernatant was removed and the pellet containing $\mathrm{OM}$ proteins was resuspended in sterile water. Proteins $\left(40 \mu \mathrm{g} \mathrm{ml}^{-1}\right)$ were boiled and separated in a $14 \%$ SDS-polyacrylamide gel and visualized following Coomassie staining with $0.1 \%$ $(\mathrm{w} / \mathrm{v})$ Coomassie blue, $10 \%(\mathrm{v} / \mathrm{v})$ acetic acid and $50 \%(\mathrm{v} / \mathrm{v})$ methanol.

Macrophage infections. Macrophage infections were performed as described by Lamothe et al. (2007). The murine macrophage-like cell line RAW 264.7 (TIB-71) was obtained from the American Type Culture Collection (Manassas, VA). Macrophage cultures were maintained in Dulbecco's modified Eagle's medium (DMEM) supplemented with $10 \%$ fetal bovine serum (FBS). Cell culture reagents were purchased from Wisent unless otherwise indicated. For macrophage infections, cells were trypsinized and used to seed sixwell plates containing glass coverslips and DMEM with $10 \%(\mathrm{v} / \mathrm{v})$ FBS. Plates were then incubated overnight at $37{ }^{\circ} \mathrm{C}$ in the presence of $5 \% \mathrm{CO}_{2}$. Bacterial strains for infections were cultured overnight and then washed twice with HEPES-buffered RPMI 1640 and resuspended in DMEM with $10 \%(\mathrm{v} / \mathrm{v})$ FBS. For control experiments bacteria were heat inactivated at $60{ }^{\circ} \mathrm{C}$ for $25 \mathrm{~min}$ prior to infection. Bacteria were added to macrophages cultured on glass coverslips at a m.o.i. of $40: 1$, centrifuged for $1 \mathrm{~min}$ at $300 \mathrm{~g}$ and incubated at $37{ }^{\circ} \mathrm{C}$ in the presence of $5 \% \mathrm{CO}_{2}$. To label lysosomes for colocalization experiments, tetramethylrhodamine (TMR)-dextran $\left(250 \mu \mathrm{g} \mathrm{ml} \mathrm{ml}^{-1}\right.$; Molecular Probes) was added to wells containing macrophages prior to infection, incubated at $37{ }^{\circ} \mathrm{C}$ with $5 \% \mathrm{CO}_{2}$ for $2 \mathrm{~h}$ and chased for $1 \mathrm{~h}$ in DMEM with $10 \%(\mathrm{v} / \mathrm{v})$ FBS. Bacteria were used to infect dextran-labelled macrophages as described above and were incubated for $4 \mathrm{~h}$ at $37{ }^{\circ} \mathrm{C}$ with $5 \% \mathrm{CO}_{2}$. At $4 \mathrm{~h}$ post-infection the external bacteria were removed by three washes with RPMI 1640 pre-warmed to $37^{\circ} \mathrm{C}$. Infected macrophages were visualized by phase-contrast and fluorescence microscopy using a Qimaging Retiga1300 cooled mono 12-bit camera on an Axioscope 2 microscope (Carl Zeiss) with a
$100 \times$ objective. Images were acquired and processed using Northern Eclipse version 6.0 software (Empix Imaging).

\section{RESULTS}

\section{Identification and mutagenesis of $r p o E$ and $m u c D$ in B. cenocepacia $\mathrm{K} 56-2$}

We previously characterized an HtrA-like serine protease that is required for growth under stress and for virulence in the rat agar bead model of pulmonary infection (Flannagan et al., 2007). In E. coli and other enteric bacteria HtrA is, in part, regulated by RpoE and both proteins are required for adaptation to stress (Dartigalongue et al., 2001). Searching for other htrA genes in the sequenced genome of $B$. cenocepacia J2315 we identified BCAL1001 and BCAL2869, which have identical DNA sequences encoding MucD, an HtrA-like serine protease. The $m u c D$ gene is the fourth gene in an operon encoding proteins homologous to RpoE, RseA, RseB and a protein of unknown function (Fig. 2a). The genetic organization of the rpoE operon in B. cenocepacia differs from that in both $E$. coli and P. aeruginosa. In these bacteria $r s e C$ is located downstream of $r s e B$ (Boucher et al., 1996; Missiakas et al., 1997); however, $r s e C$ is not present in the B. cenocepacia $r p o E$ operon. The function of $r s e C$ is not clear, as there are conflicting reports describing its function in the literature (De Las Peñas et al., 1997a; Missiakas et al., 1997). Furthermore, both $P$. aeruginosa and B. cenocepacia carry a $m u c D$ gene in the $r p o E$ operon but $E$. coli does not (De Las Peñas et al., 1997a; Missiakas et al., 1997). B. cenocepacia K56-2, which was used in this study, is clonally related to J2315 but is easier to manipulate genetically (Mahenthiralingam et al., 2000). In B. cenocepacia J2315 the entire $r p o E$ operon and flanking DNA sequences are duplicated. PCR analysis of B. cenocepacia K56-2 genomic DNA confirmed that the genes encoding RpoE, RseA, RseB and $\mathrm{MucD}$ were present and shared the same genetic organization as in J2315. RT-PCR analysis confirmed that in K56-2 these genes are co-transcribed and constitute an operon (Fig. 2b).

A B. cenocepacia K56-2 strain with an inactivated rpoE gene was created and named RSF25 (Fig. 2a). The rpoE gene was mutated in a non-polar manner by targeted integration of the suicide plasmid pGPApTp. This mutagenesis plasmid was designed to prevent polar effects on downstream genes since the orientation of the $d f r B 2$ gene and its promoter permits read-through transcription. Targeted integration was confirmed by PCR analysis and Southern blot hybridization (data not shown and Fig. 2c). In the genomic DNA from the parental strain K56-2 a band of $\sim 3 \mathrm{~kb}$ was detected, while a higher molecular mass band of $\sim 7.6 \mathrm{~kb}$ was obtained with the genomic DNA of RSF25, which was expected after integration of the suicide plasmid. Similarly, the mucD gene was inactivated by integration of a suicide plasmid as described in Methods. The $m u c D$ mutation in this strain, named RSF24, was confirmed by Southern blot hybridization, which also revealed a single higher molecular mass band 
(a)
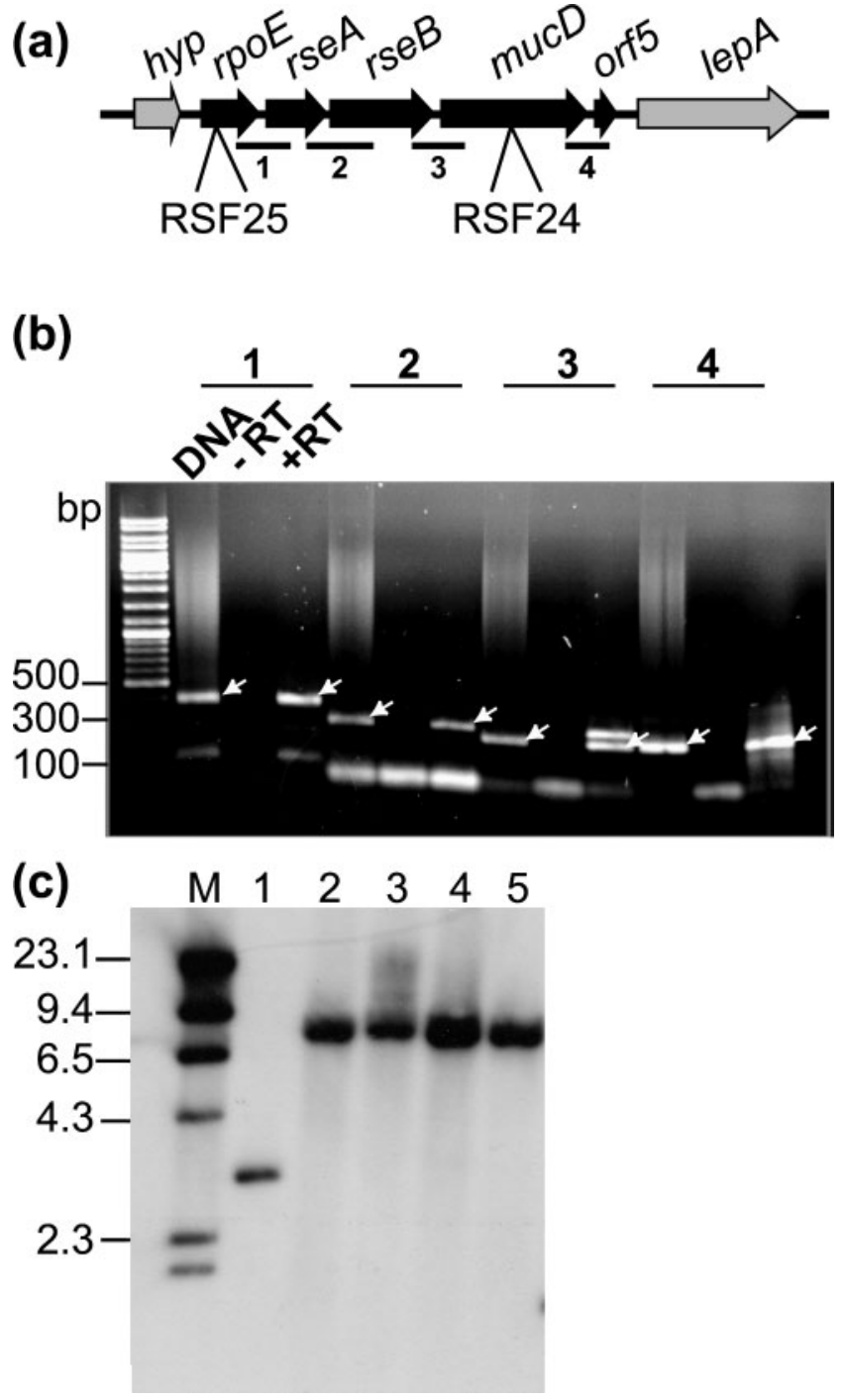

in the mutant due to the integration of the mutagenesis plasmid (data not shown). Together these data show that $r p o E$ and $m u c D$ were mutated by the integration of each respective mutagenesis plasmid. In B. cenocepacia J2315, the predicted rpoE operon is duplicated. However, the Southern blot banding patterns in the genomic DNA from K56-2 confirmed that in contrast to J2315, single copies of the rpoE and $m u c D$ genes exist in K56-2. These data are consistent with the results of Menard et al. (2007), who reported that $B$. cenocepacia K56-2 carries only one copy of the rpoE operon, which spans the genes BCAL0998 to BCAL1002.

\section{$r p o E$ is required for growth at elevated temperature}

To characterize the role of the predicted $r p o E$ gene in growth of $B$. cenocepacia under stress we tested a variety of conditions known to adversely affect other bacteria that have a mutated rpoE. No differences in efficiency of plating between the parental strain K56-2 and the rpoE mutant RSF25 were found in rich and minimal media at 30 and
Fig. 2. Genetic organization of the rpoE operon in B. cenocepacia K56-2. (a) Schematic representation of the genomic region encoding the $r p o E$ operon. Genes that are part of the $r p o E$ operon are shown in black with the gene names listed above the ORFs. hyp indicates a gene encoding a conserved hypothetical protein. orf5 also encodes a protein of unknown function. Solid black lines under intergenic regions indicate the areas analysed by RT-PCR, and denote co-transcription. The strain names, RSF25 and RSF24, are written below the genes that were insertionally mutated in these bacteria. (b) RT-PCR analysis of the rpoE genomic region in $B$. cenocepacia $\mathrm{K} 56-2$. The intergenic regions analysed are as follows: $1, r p o E$ and $r s e A ; 2, r s e A$ and $r s e B ; 3$, rse $B$ and mucD; 4, mucD and orf5. The black lines in (a) correspond to regions 1-4 from left to right. For each region, reactions were performed with DNA (positive control for amplification), -RT (negative control) and +RT (after reverse transcription). White arrows indicate the expected amplicons obtained from DNA and RT reactions. The intergenic region between orf5 and lepA was negative by RT-PCR. (c) Southern blot analysis of the rpoE mutant RSF25. Chromosomal DNA from K562 (lane 1) and from four independent colonies of RSF25 (lanes 25) was digested with $X$ hol and probed with a digoxigenin-labelled internal fragment from rpoE. $\mathrm{M}$, molecular size markers in $\mathrm{kb}$.

$37{ }^{\circ} \mathrm{C}$ (Figs 3a and 4, inset, and data not shown). Also, no differences were detected in the ability of RSF25 and K56-2 to form biofilm or to grow in the presence of $500 \mu \mathrm{g}$ polymyxin $\mathrm{B} \mathrm{ml} \mathrm{ml}^{-1}$, oxidative stress $\left(100 \mu \mathrm{M} \mathrm{H}_{2} \mathrm{O}_{2}\right.$, $100 \mu \mathrm{M}$ paraquat and xanthine/xanthine oxidase), $0.005 \%(\mathrm{w} / \mathrm{v})$ SDS, cold stress $\left(4,15\right.$ and $\left.21{ }^{\circ} \mathrm{C}\right)$, and acid conditions ( $\mathrm{pH} 7.6$ vs 5.5 and 4.5) (data not shown). In contrast, when RSF25 was cultured on LB plates at $44{ }^{\circ} \mathrm{C}$ the efficiency of plating of the mutant was reduced by 1000-fold as compared to K56-2 (Fig. 3b). In this case, both RSF25 and K56-2 strains carried the control plasmid pDA17. RSF25 carrying a pDA17 derivative expressing rpoE (pRF135) displayed increased temperature sensitivity as compared to the same strain carrying a vector control. Consistent with the notion that increased expression of $r p o E$ exacerbates the temperature-sensitive phenotype, $B$. cenocepacia K56-2 carrying plasmid pRF135 also became temperature-sensitive at $44^{\circ} \mathrm{C}$ (Fig. 3b). The rpoE mutant and parental strains carrying pRF135 also showed reduced growth at $37{ }^{\circ} \mathrm{C}$ as compared to the same strains carrying the vector control (pDA17), indicating that the bacteria are stressed even under these conditions when $r p o E$ is expressed from a plasmid (data not shown). To further characterize the temperature-sensitive phenotype K562(pDA17), RSF25(pDA17), RSF25(pRF135) and K562(pRF135) were plated on minimal media and incubated at 30 and $44{ }^{\circ} \mathrm{C}$. Under these conditions these strains grew equally well at both temperatures, indicating that the temperature-sensitive phenotype is only apparent when bacterial cells are presumably rapidly dividing in rich growth medium (data not shown). Mutant RSF24 did not demonstrate any growth defects, indicating that $m u c D$ is not required for growth under the stress conditions tested (data not shown). 

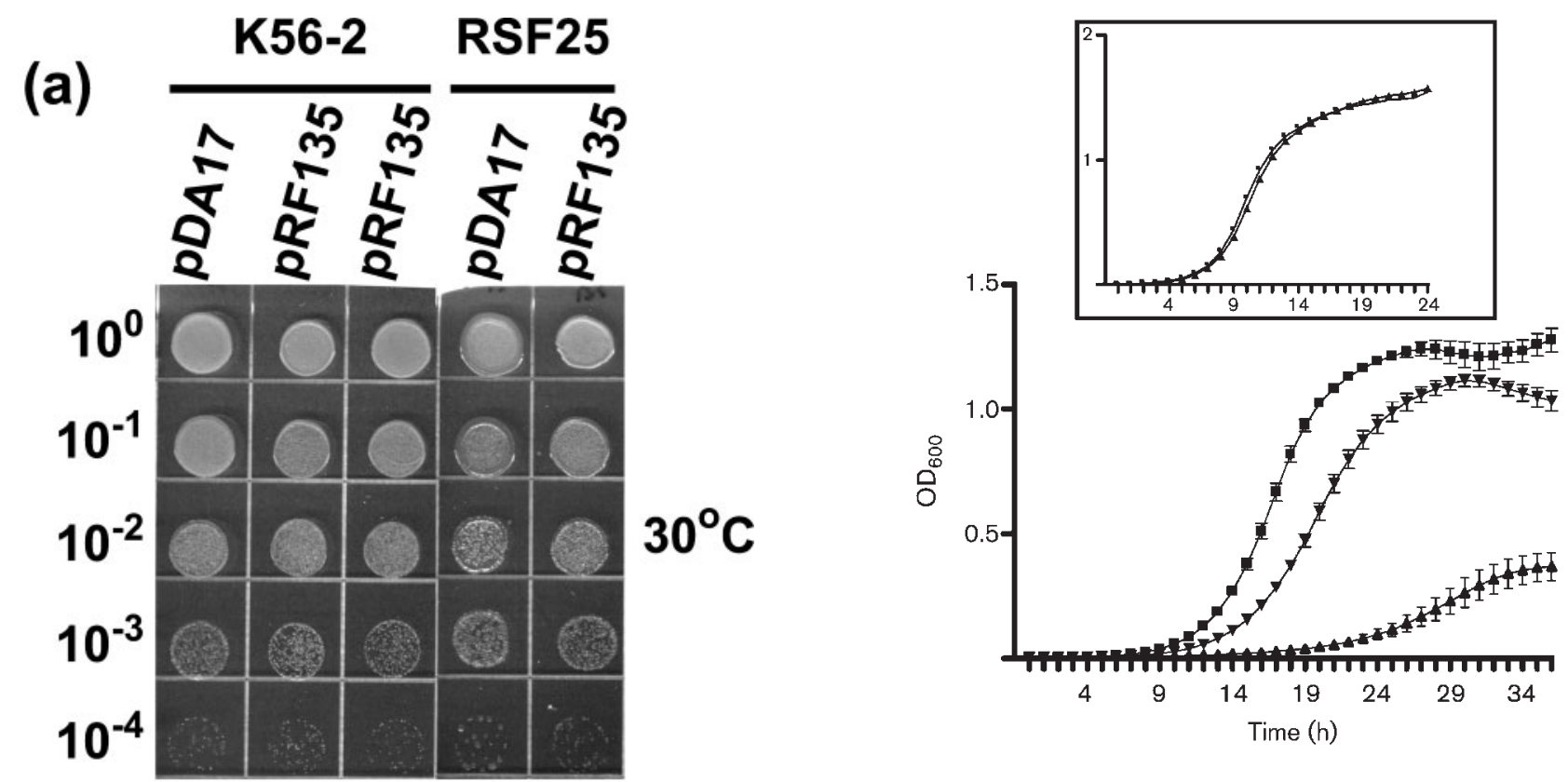

(b)

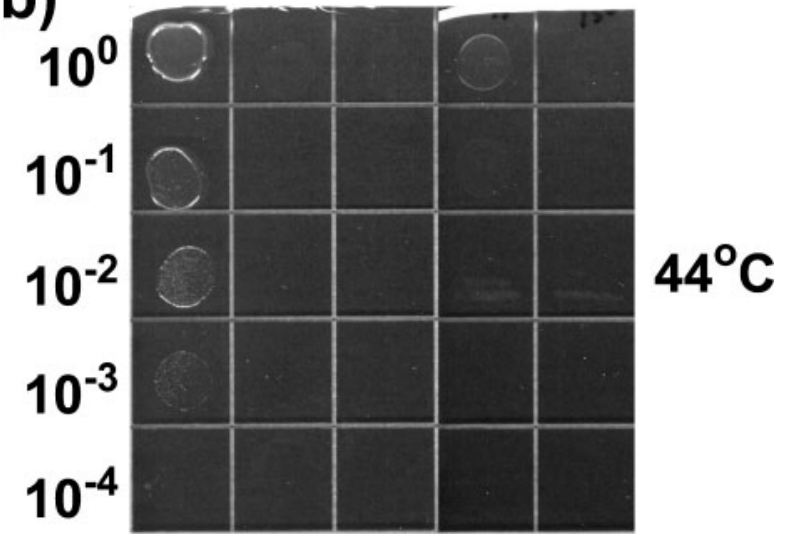

Fig. 3. Growth of $B$. cenocepacia RSF25 under conditions of thermal stress. Serial dilutions $\left(10^{\circ}-10^{-4}\right)$ of K56-2 or RSF25 carrying either pDA17 (vector control) or pRF135 $\left(r p o E^{+}\right)$were drop-plated onto LB agar and incubated at either $30{ }^{\circ} \mathrm{C}$ (a) or $44{ }^{\circ} \mathrm{C}$ (b). Two independent $\mathrm{K} 56-2$ exconjugants carrying pRF135 were analysed. Similar results were obtained in at least three independent experiments.

\section{Inactivation of rpoE compromises growth of $B$. cenocepacia under conditions of osmotic stress}

Previous work in our laboratory has shown that predicted stress response genes contribute to the growth of $B$. cenocepacia under conditions of osmotic stress (Flannagan et al., 2007). Similarly, growth of the rpoE mutant, RSF25(pDA17), was inhibited upon culture in media containing excess salt $(426 \mathrm{mM} \mathrm{NaCl})$ as compared to K56-2(pDA17) (Fig. 4). Expression of rpoE from pRF135 restored the wild-type growth phenotype to RSF25 under the same conditions, indicating that the observed defect
Fig. 4. Growth of $B$. cenocepacia RSF25 under osmotic stress. B. cenocepacia K56-2(pDA17) ( $\boldsymbol{\square}), \operatorname{RSF} 25(\mathrm{pDA} 17)(\boldsymbol{\Delta})$ and RSF25(pRF135) ( $\mathbf{\nabla})$ were cultured at $30{ }^{\circ} \mathrm{C}$ in LB medium containing $426 \mathrm{mM} \mathrm{NaCl}$. In the inset, growth of $\mathrm{K} 56-2$ and RSF25 in LB with $86 \mathrm{mM} \mathrm{NaCl}$ at $30{ }^{\circ} \mathrm{C}$ is illustrated. The experiment was performed three times, with each strain analysed in quadruplicate. Error bars indicate the SD.

was due to inactivation of rpoE alone. Growth of RSF25 was also reduced in the presence of $750 \mathrm{mM}$ sucrose (data not shown). In some instances the addition of an osmoprotectant to the culture medium can rescue the growth of bacteria under conditions of osmotic stress (Le Rudulier \& Bouillard, 1983). The addition of betaine (1$200 \mathrm{mM}$ ) to cultures of either RSF25(pDA17) or K562(pDA17) under osmotic stress had no effect on growth (data not shown). Given that the protein $\mathrm{HtrA}_{\mathrm{BCAL} 2829}$ is also required for growth under conditions of osmotic stress (Flannagan et al., 2007), we tried to complement the RSF25 growth defect by providing $\mathrm{HtrA}_{\mathrm{BCAL} 2829}$ in trans. Expression of $\mathrm{HtrA}_{\mathrm{BCAL} 2829}$ from plasmid pRF132 did not affect the growth of RSF25, indicating that the reduced growth of RSF25 is due to factors other than $\mathrm{HtrA}_{\mathrm{BCAL2829}}$ (data not shown). In contrast to the mucD mutant, RSF24 grew similarly to the parental strain K56-2.

\section{The B. cenocepacia rpoE mutant has an altered cell envelope}

RpoE in E. coli regulates many genes involved in the maintenance and biogenesis of the outer membrane (Dartigalongue et al., 2001). The rpoE mutant RSF25 was observed to 'sink' in liquid culture, which is reminiscent of strains lacking $\mathrm{O}$-antigen expression. When LPS isolated from RSF25 and K56-2 was analysed by SDS-PAGE with silver staining the $\mathrm{O}$-antigen banding patterns were 
identical (data not shown). Given that RpoE regulates outer membrane assembly and stability in other bacteria, we hypothesized that some aspect of the outer membrane must be altered in B. cenocepacia upon inactivation of rpoE. To test this, the sensitivity of RSF25 and K56-2 to SDS was analysed. These experiments revealed no differences between these strains, indicating that the membrane barrier must be intact (data not shown). It has been shown previously that $E$. coli cells under stress produce vesicles that contain periplasmic and OM proteins (McBroom \& Kuehn, 2007). However, TCA precipitation and SDS-PAGE analysis of culture supernatants recovered from RS25 and K56-2 did not reveal any differences with respect to the amount or presence/absence of proteins (data not shown).

In other bacteria, expression of exopolysaccharide and capsule can also be under the control of alternative sigma factors (Kaufusi et al., 2004; Yu et al., 1995). To look for the presence of surface-associated carbohydrates, RSF25 and K56-2 were stained with the dye Congo red, which binds $\beta$ D-glucans (Wood \& Fulcher, 1983). However, the two strains were indistinguishable in these experiments (data not shown). In contrast, when RSF25(pDA17) was cultured in the presence of the dye calcofluor white, which also interacts with $\beta$-D-glucans (Wood \& Fulcher, 1983), we observed an approximately ninefold increase in binding of the dye $(P<0.0001)$ compared to the parental strain K56-2(pDA17) (Fig. 5a-c). Expression of rpoE in trans restored calcofluor white binding almost back to wild-type levels $(0.3500 \pm 0.039) \quad$ (Fig. 5a-c). These data suggest that inactivation of rpoE leads to the expression or unmasking of carbohydrates on the cell surface. To determine if calcofluor white binding was due to the synthesis of capsule we used India ink staining (Richardson \& Sadoff, 1977). Klebsiella pneumoniae expresses capsule that can be detected by India ink staining and was used as a positive control. However, staining with India ink did not reveal any differences between K56-2 and RSF25. Although these experiments cannot rule out the absence of capsule, we conclude that calcofluor white binds a surface carbohydrate structure whose expression is modulated by RpoE. We also looked for altered patterns of OM protein expression in RSF25 and K56-2 by SDS-PAGE analysis. OM proteins from RSF25(pDA17) showed differences in protein banding as compared to K56-2(pDA17) and RSF25(pRF135), which disappeared after complementation of the $r p o E$ defect (data not shown). Together, these results suggest that inactivation of $r p o E$ leads to alterations in the cell envelope of $B$. cenocepacia K56-2.

\section{Intracellular rpoE-deficient B. cenocepacia cannot delay phagolysosomal fusion in macrophages}

Previous work in our laboratory has demonstrated that in macrophages $B$. cenocepacia resides in a membrane-bound compartment that does not fuse with lysosomes, at least during the first few hours post-infection (Lamothe et al.,

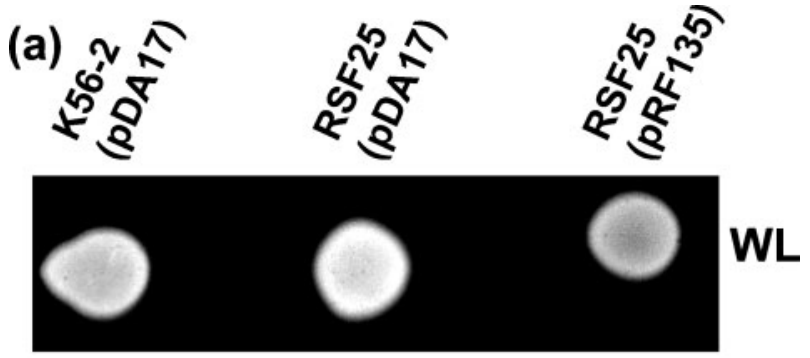

(b)

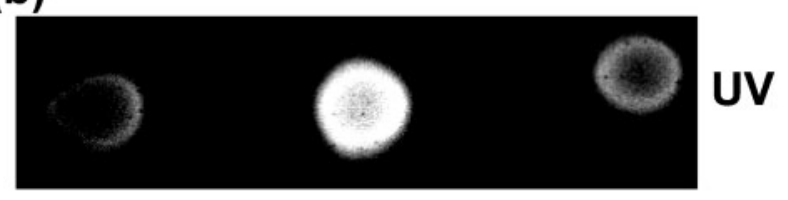

(c)

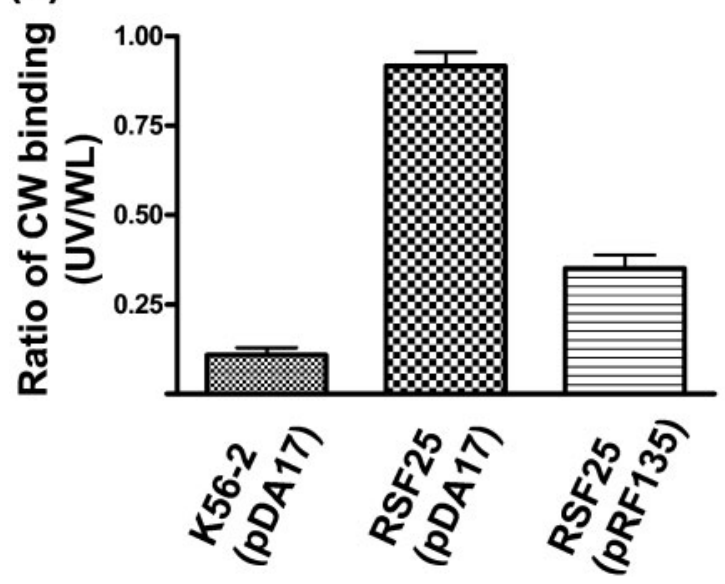

Fig. 5. Binding of calcofluor white to $B$. cenocepacia RSF25. Cell suspensions of $B$. cenocepacia K56-2 (carrying pDA17) and RSF25 (carrying pDA17 or pRF135) were drop-plated onto LB agar containing $0.002 \%(\mathrm{w} / \mathrm{v})$ calcofluor white and incubated for $24 \mathrm{~h}$ at $30{ }^{\circ} \mathrm{C}$. Plates were imaged with exposure to white light (WL) (a) and UV light (b). (c) Bar graph showing the densitometric ratio of calcofluor white $(\mathrm{CW})$ binding. Values were obtained by dividing UV light pixel intensities by WL pixel intensities for individual spots. Error bars denote the SEM obtained from three independent experiments with each strain analysed in quadruplicate.

2007). We have also shown that the delay in phagolysosomal fusion requires viable bacteria (Lamothe et al., 2007) and does not take place in B. cenocepacia mutants showing a defect in intracellular survival (Keith \& Valvano, 2007; Maloney \& Valvano, 2006). To assess whether RpoE controls functions required for the intracellular lifestyle of B. cenocepacia we performed infection experiments in RAW264.7 macrophages with the rpoE mutant RSF25. Since B. cenocepacia cannot replicate in macrophages and is extremely resistant to most antibiotics, classical methods to assess intracellular bacterial survival based on the selective killing of extracellular bacteria with host-cell-impermeable antibiotics are not possible (Lamothe et al., 2007). 
Therefore, we use single-cell analysis by fluorescence microscopy, in macrophages preloaded with a fluid-phase marker. Dextran, a fluid-phase probe for the endocytic pathway, is commonly used to pre-label the lysosomal compartment (Eissenberg et al., 1988; Rodriguez et al., 2006; Wiater et al., 1998). Macrophages were exposed to fluorescent dextran for $3 \mathrm{~h}$ and then infected with either K56-2 or RSF25. In both cases, bacteria can be seen within membrane-bound compartments (Fig. 6a, b). However, in contrast to the parental strain, K56-2, where $41.1 \% \pm 3.5$ of bacteria-containing vacuoles labelled red with dextran, $89.2 \% \pm 6.8$ of the vacuoles containing RSF25 were fluorescent indicating dextran colocalization (Fig. 6c). As a control, heat-inactivated $\mathrm{K} 56-2$ cells were used to infect macrophages and at $2 \mathrm{~h}$ post-infection $94.8 \% \pm 2.4$ of the bacteria-containing vacuoles were fluorescent, indicating fusion of the membrane-bound compartment with lysosomes. Complementation of RSF25 was not performed in these experiments because, as stated above, in B. cenocepacia expression of rpoE from a plasmid even at $37{ }^{\circ} \mathrm{C}$ adversely affects growth. Nevertheless, these experiments show that, similar to heat-killed K56-2, the RSF25 rpoE mutant is less able to promote a delay in the fusion of lysosomes with BcCVs. Although these experiments do not directly demonstrate a defect in intracellular survival, previous work in our laboratory has demonstrated that failure to delay phagolysosomal fusion causes rapid degradation of bacterial cells in the lysosomes (Keith \& Valvano, 2007; Maloney \& Valvano, 2006).

\section{DISCUSSION}

A search for HtrA-like serine proteases in the B. cenocepacia J2315 genome allowed us to identify an operon encoding the alternative sigma factor RpoE, and its regulatory proteins RseA and RseB. This operon is in a duplicated genomic fragment in strain J2315, but it is present as a single copy in strain K56-2, which we used for the genetic manipulations in this study. The third ORF downstream of $r p o E$, $m u c D$, encodes a predicted HtrA protease, and it is followed by a gene of unknown function. While inactivation of $m u c D$ produced no phenotype, mutagenesis of $r p o E$ resulted in a strain that was compromised for growth under certain stress conditions including elevated temperature and high osmolarity. Previous work that characterized an rpoE mutant in B. cepacia, another member of the Burkholderia cepacia complex, suggested that RpoE in this bacterium does not contribute significantly to the stress response (Devescovi \& Venturi, 2006). However, our results showed that the B. cenocepacia RSF25 rpoE mutant exhibited growth defects under elevated temperature and osmolarity, and displayed cell envelope alterations. Previously, we have shown that $B$. cenocepacia requires the HtrA protein, BCAL2829, for growth under stress and

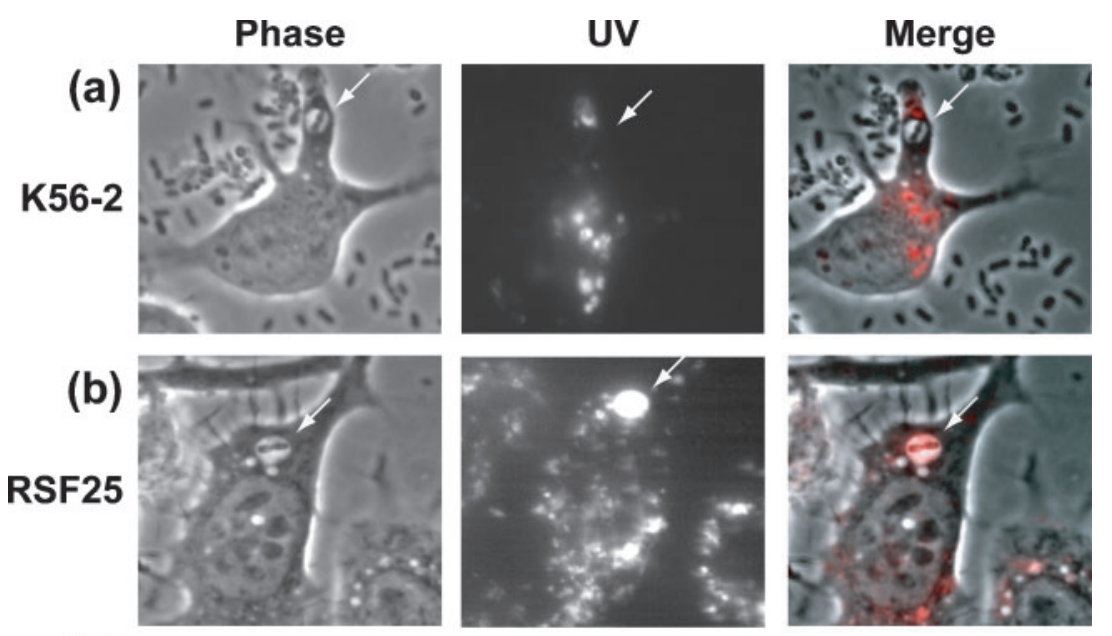

(c)

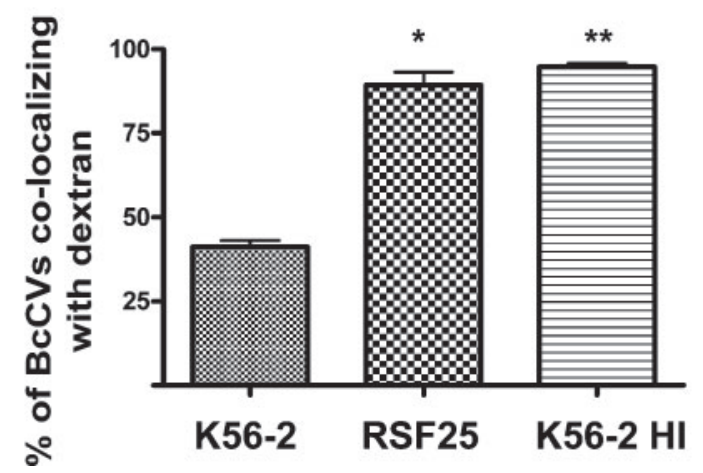

Fig. 6. The rpoE mutant RSF25 co-localizes with dextran-labelled lysosomes. RAW 264.7 macrophages were labelled with $250 \mu \mathrm{g}$ TMRdextran $\mathrm{ml}^{-1}$ and then infected with either wild-type (K56-2) or mutant (RSF25) bacteria at a m.o.i. of 40 . Infected macrophages were analysed at $4 \mathrm{~h}$ post-infection. (a) K56-2 bacteria are found within membrane-bound compartments that do not co-localize with dextran. (b) RSF25 bacteria are found within membrane-bound vacuoles that are fluorescent. White arrows indicate bacteria within a membrane-bound compartment. (a) and (b) are representative images of those obtained from at least three independent experiments. Phase, phase-contrast microscopy; UV, fluorescence microscopy of the same field; Merge, merged images. (c) Bar graph representing the average percentage of $\mathrm{BcCVs}$ that co-localize with TMR-dextran for K56-2, RSF25 and a heat-inactivated $(\mathrm{HI}) \mathrm{K} 56-2$ control. Error bars indicate SE. Significant differences were determined using the unpaired $t$-test from at least three independent experiments. ${ }^{*}, P<0.0005$; **,$P<0.0001$ when compared to wild-type K56-2. RSF25 and K56-2 (HI) did not differ significantly. 
for survival in vivo (Flannagan et al., 2007). However, inactivation of the $m u c D$ gene did not compromise growth of $B$. cenocepacia under the conditions tested. Bioinformatic analysis of the B. cenocepacia J2315 genome reveals that this bacterium encodes five different HtrA-like serine proteases and it is conceivable that these HtrA proteins may have redundant functions that compensate for a $m u c D$ mutation. Although our experiments do not rule out the possibility that MucD functions in some capacity in the B. cenocepacia stress response they do indicate that this gene is dispensable in the presence of the remaining $h$ trA genes.

The mechanism for activating RpoE-mediated transcription is well conserved in other bacteria (Cezairliyan \& Sauer, 2007; Craig et al., 2002; Korbsrisate et al., 2005; Martinez-Salazar et al., 1996; Mathur et al., 2007; Missiakas \& Raina, 1998; Yu et al. 1995) and follows the misfolding of porin protein precursors in the periplasm, which trigger a proteolytic cascade involving DegS (Walsh et al., 2003) and YaeL (Alba et al., 2002; Kanehara et al., 2002) resulting in cleavage of the anti-sigma factor RseA followed by release of RpoE (Kanehara et al., 2002). The mechanism of RpoE activation in B. cenocepacia remains to be characterized, but given that genes encoding RseA and RseB are present in the genome within the rpoE operon, it is likely that the mechanism of RpoE activation is also conserved in $B$. cenocepacia. In E. coli, $\operatorname{deg} P$ is an RpoE-regulated gene that encodes an HtrA-like serine protease and is transcribed upon exposure to certain stress conditions (Dartigalongue et al., 2001; Lipinska et al., 1988). DegP degrades misfolded proteins that accumulate in the periplasmic space (Clausen et al., 2002). Previously we characterized an HtrA protease (BCAL2829) in B. cenocepacia that was required for growth under heat and osmotic stress, mirroring the phenotype of the rpoE mutant (Flannagan et al., 2007). This suggested that RpoE could in fact regulate BCAL2829, but attempts to complement the growth defects of RSF25 through expression of BCAL2829 failed. This indicates either that $h$ trA $A_{\mathrm{BCAL} 2829}$ is not part of the $r p o E$ regulon or that other genes required for growth under stress, in addition to BCAL2829, are not expressed in the rpoE mutant.

In other bacteria, such as Salmonella enterica, RpoE is critical for intracellular survival and virulence in mice (Humphreys et al., 1999). Previous work has shown that $B$. cenocepacia can survive within amoebae and macrophages and has suggested that intracellular survival may contribute to the persistence of $B$. cenocepacia during infection (Lamothe et al., 2007; Saini et al., 1999). To determine if the $r p o E$ gene plays any role in the intracellular survival of B. cenocepacia we turned to a macrophage model of infection. After phagocytosis by murine macrophages, wild-type $B$. cenocepacia delay the maturation of the $\mathrm{BcCV}$ and at $4 \mathrm{~h}$ post-infection intracellular wild-type bacteria that are within a membrane-bound compartment do not fuse with lysosomes (Lamothe et al., 2007). The dextran colocalization experiments performed in our study demonstrate the requirement for RpoE for B. cenocepacia to cause this delay. Although not directly demonstrated, the rapid trafficking of rpoE-defective $B$. cenocepacia to lysosomes is likely to be associated with loss of bacterial viability. This notion is supported by our previous observations demonstrating that every mutant created thus far in B. cenocepacia that fails to delay the maturation of the $\mathrm{BcCV}$ is destroyed in the lysosomes (Keith \& Valvano, 2007; Maloney \& Valvano, 2006). The specific mechanism employed by $B$. cenocepacia to delay maturation of the $\mathrm{BcCV}$ is currently unknown. However, our data suggest that it may require the expression of a gene or genes that are under the control of RpoE, and therefore respond to extracytoplasmic stress.

In summary, our data show that RpoE in B. cenocepacia is required for growth under stress and regulates some of the biological properties of the bacterial cell envelope. We have also shown that RpoE is required for the normal maturation of $\mathrm{BcCVs}$ in macrophages. The bacterial stress response in $B$. cenocepacia has only recently begun to be elucidated and further studies, currently under way in our laboratory, should shed light on the components of the RpoE regulon, and more importantly on the molecular mechanism explaining how this bacterium can persist in many different environments including the respiratory tract of CF patients.

\section{ACKNOWLEDGEMENTS}

We thank the members of our laboratory for helpful discussions and J. Parkhill for providing access to the draft annotation of $B$. cenocepacia J2315. We specifically thank T. Stephens, S. Loutet and K. Maloney for critically reading the manuscript. This work was supported by grants from the Canadian Cystic Fibrosis Foundation and a special program grant in memory of Michael O'Reilly from the Canadian Cystic Fibrosis Foundation in partnership with the Canadian Institutes of Health Research (to M.A.V.). R.S.F. was supported by a graduate student fellowship from the Canadian Cystic Fibrosis Foundation. M. A. V. holds a Canada Research Chair in Infectious Diseases and Microbial Pathogenesis.

\section{REFERENCES}

Alba, B. M., Leeds, J. A., Onufryk, C., Lu, C. Z. \& Gross, C. A. (2002). DegS and YaeL participate sequentially in the cleavage of RseA to activate the $\sigma^{\mathrm{E}}$-dependent extracytoplasmic stress response. Genes Dev 16, 2156-2168.

Boucher, J. C., Martinez-Salazar, J., Schurr, M. J., Mudd, M. H., Yu, H. \& Deretic, V. (1996). Two distinct loci affecting conversion to mucoidy in Pseudomonas aeruginosa in cystic fibrosis encode homologs of the serine protease HtrA. J Bacteriol 178, 511-523.

Brisse, S., Cordevant, C., Vandamme, P., Bidet, P., Loukil, C., Chabanon, G., Lange, M. \& Bingen, E. (2004). Species distribution and ribotype diversity of Burkholderia cepacia complex isolates from French patients with cystic fibrosis. J Clin Microbiol 42, 4824-4827.

Carlone, G. M., Thomas, M. L., Rumschlag, H. S. \& Sottnek, F. O. (1986). Rapid microprocedure for isolating detergent-insoluble outer membrane proteins from Haemophilus species. J Clin Microbiol 24, $330-332$. 
Cezairliyan, B. O. \& Sauer, R. T. (2007). Inhibition of regulated proteolysis by RseB. Proc Natl Acad Sci U S A 104, 3771-3776.

Chaba, R., Grigorova, I. L., Flynn, J. M., Baker, T. A. \& Gross, C. A. (2007). Design principles of the proteolytic cascade governing the $\sigma^{\mathrm{E}}$ mediated envelope stress response in Escherichia coli: keys to graded, buffered, and rapid signal transduction. Genes Dev 21, 124-136.

Clausen, T., Southan, C. \& Ehrmann, M. (2002). The HtrA family of proteases: implications for protein composition and cell fate. Mol Cell 10, 443-455.

Coenye, T. \& Vandamme, P. (2003). Diversity and significance of Burkholderia species occupying diverse ecological niches. Environ Microbiol 5, 719-729.

Coenye, T., Vandamme, P., LiPuma, J. J., Govan, J. R. \& Mahenthiralingam, E. (2003). Updated version of the Burkholderia cepacia complex experimental strain panel. J Clin Microbiol 41, 2797-2798.

Cohen, S. N., Chang, A. C. \& Hsu, L. (1972). Nonchromosomal antibiotic resistance in bacteria: genetic transformation of Escherichia coli by R-factor DNA. Proc Natl Acad Sci U S A 69, 2110-2114.

Courtney, J. M., Dunbar, K. E., McDowell, A., Moore, J. E., Warke, T. J., Stevenson, M. \& Elborn, J. S. (2004). Clinical outcome of Burkholderia cepacia complex infection in cystic fibrosis adults. J Cyst Fibros 3, 93-98.

Craig, J. E., Nobbs, A. \& High, N. J. (2002). The extracytoplasmic sigma factor, $\sigma^{\mathrm{E}}$, is required for intracellular survival of nontypeable Haemophilus influenzae in $\mathrm{J} 774$ macrophages. Infect Immun 70, 708-715.

Dartigalongue, C., Missiakas, D. \& Raina, S. (2001). Characterization of the Escherichia coli $\sigma^{\mathrm{E}}$ regulon. J Biol Chem 276, 20866-20875.

De Las Peñas, A., Connolly, L. \& Gross, C. A. (1997a). The $\sigma^{\mathrm{E}}-$ mediated response to extracytoplasmic stress in Escherichia coli is transduced by RseA and RseB, two negative regulators of $\sigma^{\mathrm{E}}$. Mol Microbiol 24, 373-385.

De Las Peñas, A., Connolly, L. \& Gross, C. A. (1997b). $\sigma^{\mathrm{E}}$ is an essential sigma factor in Escherichia coli. J Bacteriol 179, 6862-6864.

Devescovi, G. \& Venturi, V. (2006). The Burkholderia cepacia rpoE gene is not involved in exopolysaccharide production and onion pathogenicity. Can J Microbiol 52, 260-265.

Eissenberg, L. G., Schlesinger, P. H. \& Goldman, W. E. (1988). Phagosome-lysosome fusion in P388D1 macrophages infected with Histoplasma capsulatum. J Leukoc Biol 43, 483-491.

Figurski, D. H. \& Helinski, D. R. (1979). Replication of an origincontaining derivative of plasmid RK2 dependent on a plasmid function provided in trans. Proc Natl Acad Sci U S A 76, 1648-1652.

Filutowicz, M. \& Rakowski, S. A. (1998). Regulatory implications of protein assemblies at the $\gamma$ origin of plasmid R6K - a review. Gene 223, 195-204.

Flannagan, R. S., Aubert, D., Kooi, C., Sokol, P. A. \& Valvano, M. A. (2007). Burkholderia cenocepacia requires a periplasmic HtrA protease for growth under thermal and osmotic stress and for survival in vivo. Infect Immun 75, 1679-1689.

Flynn, J. M., Levchenko, I., Sauer, R. T. \& Baker, T. A. (2004). Modulating substrate choice: the SspB adaptor delivers a regulator of the extracytoplasmic-stress response to the AAA + protease ClpXP for degradation. Genes Dev 18, 2292-2301.

Govan, J. R., Brown, P. H., Maddison, J., Doherty, C. J., Nelson, J. W., Dodd, M., Greening, A. P. \& Webb, A. K. (1993). Evidence for transmission of Pseudomonas cepacia by social contact in cystic fibrosis. Lancet 342, 15-19.

Humphreys, S., Stevenson, A., Bacon, A., Weinhardt, A. B. \& Roberts, M. (1999). The alternative sigma factor, $\sigma^{\mathrm{E}}$, is critically important for the virulence of Salmonella typhimurium. Infect Immun 67, 1560-1568.

Isles, A., Maclusky, I., Corey, M., Gold, R., Prober, C., Fleming, P. \& Levison, H. (1984). Pseudomonas cepacia infection in cystic fibrosis: an emerging problem. J Pediatr 104, 206-210.

Jones, A. M., Dodd, M. E., Govan, J. R., Barcus, V., Doherty, C. J., Morris, J. \& Webb, A. K. (2004). Burkholderia cenocepacia and Burkholderia multivorans: influence on survival in cystic fibrosis. Thorax 59, 948-951.

Kanehara, K., Ito, K. \& Akiyama, Y. (2002). YaeL (EcfE) activates the $\sigma^{\mathrm{E}}$ pathway of stress response through a site-2 cleavage of anti- $\sigma^{\mathrm{E}}$, RseA. Genes Dev 16, 2147-2155.

Kaufusi, P. H., Forsberg, L. S., Tittabutr, P. \& Borthakur, D. (2004). Regulation of exopolysaccharide synthesis in Rhizobium sp. strain TAL1145 involves an alternative sigma factor gene, rpoH2. Microbiology 150, 3473-3482.

Keith, K. E. \& Valvano, M. A. (2007). Characterization of SodC, a periplasmic superoxide dismutase from Burkholderia cenocepacia. Infect Immun 75, 2451-2460.

Korbsrisate, S., Vanaporn, M., Kerdsuk, P., Kespichayawattana, W., Vattanaviboon, P., Kiatpapan, P. \& Lertmemongkolchai, G. (2005). The Burkholderia pseudomallei $\mathrm{RpoE}$ (AlgU) operon is involved in environmental stress tolerance and biofilm formation. FEMS Microbiol Lett 252, 243-249.

Lamothe, J., Huynh, K. K., Grinstein, S. \& Valvano, M. A. (2007). Intracellular survival of Burkholderia cenocepacia in macrophages is associated with a delay in the maturation of bacteria-containing vacuoles. Cell Microbiol 9, 40-53.

Le Rudulier, D. \& Bouillard, L. (1983). Glycine betaine, an osmotic effector in Klebsiella pneumoniae and other members of the Enterobacteriaceae. Appl Environ Microbiol 46, 152-159.

Lefebre, M. D. \& Valvano, M. A. (2002). Construction and evaluation of plasmid vectors optimized for constitutive and regulated gene expression in Burkholderia cepacia complex isolates. Appl Environ Microbiol 68, 5956-5964.

Lipinska, B., Sharma, S. \& Georgopoulos, C. (1988). Sequence analysis and regulation of the htrA gene of Escherichia coli: a $\sigma^{32}$ independent mechanism of heat-inducible transcription. Nucleic Acids Res 16, 10053-10067.

LiPuma, J. J. (2005). Update on the Burkholderia cepacia complex. Curr Opin Pulm Med 11, 528-533.

LiPuma, J. J., Dasen, S. E., Nielson, D. W., Stern, R. C. \& Stull, T. L. (1990). Person-to-person transmission of Pseudomonas cepacia between patients with cystic fibrosis. Lancet 336, 1094-1096.

Mahenthiralingam, E. \& Vandamme, P. (2005). Taxonomy and pathogenesis of the Burkholderia cepacia complex. Chron Respir Dis 2, 209-217.

Mahenthiralingam, E., Coenye, T., Chung, J. W., Speert, D. P., Govan, J. R., Taylor, P. \& Vandamme, P. (2000). Diagnostically and experimentally useful panel of strains from the Burkholderia cepacia complex. J Clin Microbiol 38, 910-913.

Maloney, K. E. \& Valvano, M. A. (2006). The $m g t C$ gene of Burkholderia cenocepacia is required for growth under magnesium limitation conditions and intracellular survival in macrophages. Infect Immun 74, 5477-5486.

Manno, G., Dalmastri, C., Tabacchioni, S., Vandamme, P., Lorini, R., Minicucci, L., Romano, L., Giannattasio, A., Chiarini, L. \& Bevivino, A. (2004). Epidemiology and clinical course of Burkholderia cepacia complex infections, particularly those caused by different Burkholderia cenocepacia strains, among patients attending an Italian cystic fibrosis center. J Clin Microbiol 42, 1491-1497. 
Martinez-Salazar, J. M., Moreno, S., Najera, R., Boucher, J. C., Espin, G., Soberon-Chavez, G. \& Deretic, V. (1996). Characterization of the genes coding for the putative sigma factor $\mathrm{Alg} \mathrm{U}$ and its regulators MucA, MucB, MucC, and MucD in Azotobacter vinelandii and evaluation of their roles in alginate biosynthesis. $J$ Bacteriol 178, 1800-1808.

Mathur, J., Davis, B. M. \& Waldor, M. K. (2007). Antimicrobial peptides activate the Vibrio cholerae $\sigma^{\mathrm{E}}$ regulon through an OmpUdependent signalling pathway. Mol Microbiol 63, 848-858.

McBroom, A. J. \& Kuehn, M. J. (2007). Release of outer membrane vesicles by Gram-negative bacteria is a novel envelope stress response. Mol Microbiol 63, 545-558.

Menard, A., Estrada de Los Santos, P., Graindorge, A. \& Cournoyer, B. (2007). Architecture of Burkholderia cepacia complex sigma 70 gene family: evidence of alternative primary and clade-specific factors, and genomic instability. BMC Genomics 8, 308 (Epub ahead of print)

Miller, V. L. \& Mekalanos, J. J. (1988). A novel suicide vector and its use in construction of insertion mutations: osmoregulation of outer membrane proteins and virulence determinants in Vibrio cholerae requires toxR. J Bacteriol 170, 2575-2583.

Missiakas, D. \& Raina, S. (1998). The extracytoplasmic function sigma factors: role and regulation. Mol Microbiol 28, 1059-1066.

Missiakas, D., Mayer, M. P., Lemaire, M., Georgopoulos, C. \& Raina, S. (1997). Modulation of the Escherichia coli $\sigma^{\mathrm{E}}$ (RpoE) heat-shock transcription-factor activity by the RseA, RseB and RseC proteins. Mol Microbiol 24, 355-371.

Ortega, X., Hunt, T. A., Loutet, S., Vinion-Dubiel, A. D., Datta, A., Choudhury, B., Goldberg, J. B., Carlson, R. \& Valvano, M. A. (2005). Reconstitution of O-specific lipopolysaccharide expression in Burkholderia cenocepacia strain J2315, which is associated with transmissible infections in patients with cystic fibrosis. J Bacteriol 187, 1324-1333.

Raina, S., Missiakas, D. \& Georgopoulos, C. (1995). The rpoE gene encoding the $\sigma^{\mathrm{E}}\left(\sigma^{24}\right)$ heat shock sigma factor of Escherichia coli. EMBO J 14, 1043-1055.

Reik, R., Spilker, T. \& Lipuma, J. J. (2005). Distribution of Burkholderia cepacia complex species among isolates recovered from persons with or without cystic fibrosis. J Clin Microbiol 43, 2926-2928.

Rezuchova, B., Miticka, H., Homerova, D., Roberts, M. \& Kormanec, J. (2003). New members of the Escherichia coli $\sigma^{\mathrm{E}}$ regulon identified by a two-plasmid system. FEMS Microbiol Lett 225, 1-7.

Richardson, W. P. \& Sadoff, J. C. (1977). Production of a capsule of Neisseria gonorrhoeae. Infect Immun 15, 663-664.
Rodriguez, N. E., Gaur, U. \& Wilson, M. E. (2006). Role of caveolae in Leishmania chagasi phagocytosis and intracellular survival in macrophages. Cell Microbiol 8, 1106-1120.

Saini, L. S., Galsworthy, S. B., John, M. A. \& Valvano, M. A. (1999). Intracellular survival of Burkholderia cepacia complex isolates in the presence of macrophage cell activation. Microbiology 145, 3465-3475.

Sambrook, J., Fritsch, E. F. \& Maniatis, T. (1990). Molecular Cloning: a Laboratory Manual, 2nd edn. Cold Spring Harbor, NY: Cold Spring Harbor Laboratory.

Smith, D. L., Gumery, L. B., Smith, E. G., Stableforth, D. E., Kaufmann, M. E. \& Pitt, T. L. (1993). Epidemic of Pseudomonas cepacia in an adult cystic fibrosis unit: evidence of person-to-person transmission. J Clin Microbiol 31, 3017-3022.

Speert, D. P., Henry, D., Vandamme, P., Corey, M. \& Mahenthiralingam, E. (2002). Epidemiology of Burkholderia cepacia complex in patients with cystic fibrosis, Canada. Emerg Infect Dis 8, 181-187.

Thomassen, M. J., Demko, C. A., Klinger, J. D. \& Stern, R. C. (1985). Pseudomonas cepacia colonization among patients with cystic fibrosis. A new opportunist. Am Rev Respir Dis 131, 791-796.

Walsh, N. P., Alba, B. M., Bose, B., Gross, C. A. \& Sauer, R. T. (2003). OMP peptide signals initiate the envelope-stress response by activating DegS protease via relief of inhibition mediated by its PDZ domain. Cell 113, 61-71.

Wiater, L. A., Dunn, K., Maxfield, F. R. \& Shuman, H. A. (1998). Early events in phagosome establishment are required for intracellular survival of Legionella pneumophila. Infect Immun 66, 4450-4460.

Wood, P. J. \& Fulcher, R. G. (1983). Dye interactions. A basis for specific detection and histochemistry of polysaccharides. J Histochem Cytochem 31, 823-826.

Yu, H., Schurr, M. J. \& Deretic, V. (1995). Functional equivalence of Escherichia coli $\sigma^{\mathrm{E}}$ and Pseudomonas aeruginosa AlgU: E. coli rpoE restores mucoidy and reduces sensitivity to reactive oxygen intermediates in alg $U$ mutants of $P$. aeruginosa. J Bacteriol 177, 3259-3268.

Zhou, J., Chen, Y., Tabibi, S., Alba, L., Garber, E. \& Saiman, L. (2007). Antimicrobial susceptibility and synergy studies of Burkholderia cepacia complex isolated from patients with cystic fibrosis. Antimicrob Agents Chemother 51, 1085-1088.

Edited by: J. G. Shaw 